\title{
Knowledge, Attitude and Practice of Hand washing among Street vendors in Campus of Universitas Padjadjaran, West Java from June- November 2012
}

\author{
Tajul Al Adib, ${ }^{1}$ Ardini S. Raksanagara, ${ }^{2}$ Dewi Hawani, ${ }^{3}$ Elsa Puji Setiawati ${ }^{2}$ \\ ${ }^{1}$ Faculty of Medicine, Universitas Padjadjaran, ${ }^{2}$ Department of Public Health, Faculty of \\ Medicine Universitas Padjadjaran ${ }^{3}$ Department of Child Health Faculty of Medicine Universitas \\ Padjadjaran/Dr. Hasan Sadikin General Hospital Bandung
}

\begin{abstract}
Background: Hand washing is a moderate step in preventing communicable diseases. Communicable diseases like diarrhea and respiratory tract infection can be reduced significantly just by practicing hand washing. Most of the people already knew how to wash their hand, but some of them still did not understand the objective and the correct ways of performing hand washing. The aim of the study was to evaluate knowledge, attitude and practice of hand washing among street vendors.

Methods: A descriptive study was conducted to 30 street vendors at the gate of Universitas Padjadjaran Campus from June to November 2012. The inclusion criterias were street vendors involved in food preparation, cooking, mixing, and willing to participate in this study. A questionnaire was developed to identify the knowledge, attitude and practice of hand washing. The level of the variable measured was divided into 3 categories: good, moderate, and poor. The collected data were analyzed and presented in table.

Results: There were $12 / 30$ of street vendors classified as having moderate knowledge and 25/30 as having good attitude and good practice of hand washing.

Conclusions: The street vendors at the gate of Universitas Padjadjaran Campus had moderate knowledge, good attitude and good practice of hand washing. [AMJ.2015;2(3):369-74]
\end{abstract}

Keywords: Attitude, hand washing, knowledge, practice, street vendors

\section{Introduction}

Global Burden of Disease is a study conducted by the World Bank since $1992 .{ }^{1}$ The main objective of the study is to assess mortality due to disease, injury and risk factor. According to this study, four out of ten in the Top 10 causes of death in the world are communicable disease. ${ }^{2} \mathrm{~A}$ communicable disease is a disease that can be transmitted from a person, animal or inanimate source to another person. The transmission can be directly, via intermediate host or by vector. ${ }^{3}$ Communicable disease that uses food as the medium is known as food borne disease.

Food borne disease is defined as a group of diseases that can be transmitted to human by consuming food already contaminated by pathogenic microorganisms. About 31 pathogens are known as the etiology of food borne disease and norovirus, Salmonella nontyphoidal, Clostridium perfringens, Campylobacter spp. and Staphylococcus aureus are in the top 5. ${ }^{4}$ There are more than 250 food borne diseases that have been known including cholera, typhoid fever and hepatitis $A$ and most of the diseases come with symptom of diarrhea. ${ }^{5}$

Diarrhea was characterized by unformed or liquid stool with more than 3 times of defecation a day. In 2004, there were about two millions of death caused by diarrhea. ${ }^{6}$ Diarrhea can be transmitted between people, by poor personal hygiene, food and water. ${ }^{7}$ However, the incidence of this disease can be reduced by practicing hand washing. A study shows that hand washing can reduce the incidence of diarrhea by $25 \%{ }^{8}$ With proper practice of hand washing, the chance of transmitting and being infected can be reduced.

Street vendors are defined as a vendor

Correspondence: Tajul Al Adib, Faculty of Medicine, Universitas Padjadjaran, Jalan Raya Bandung-Sumedang Km.21, Jatinangor, Sumedang, Indonesia, Phone: +6281910590338, +60194076912 Email: are_deep89@yahoo.com 


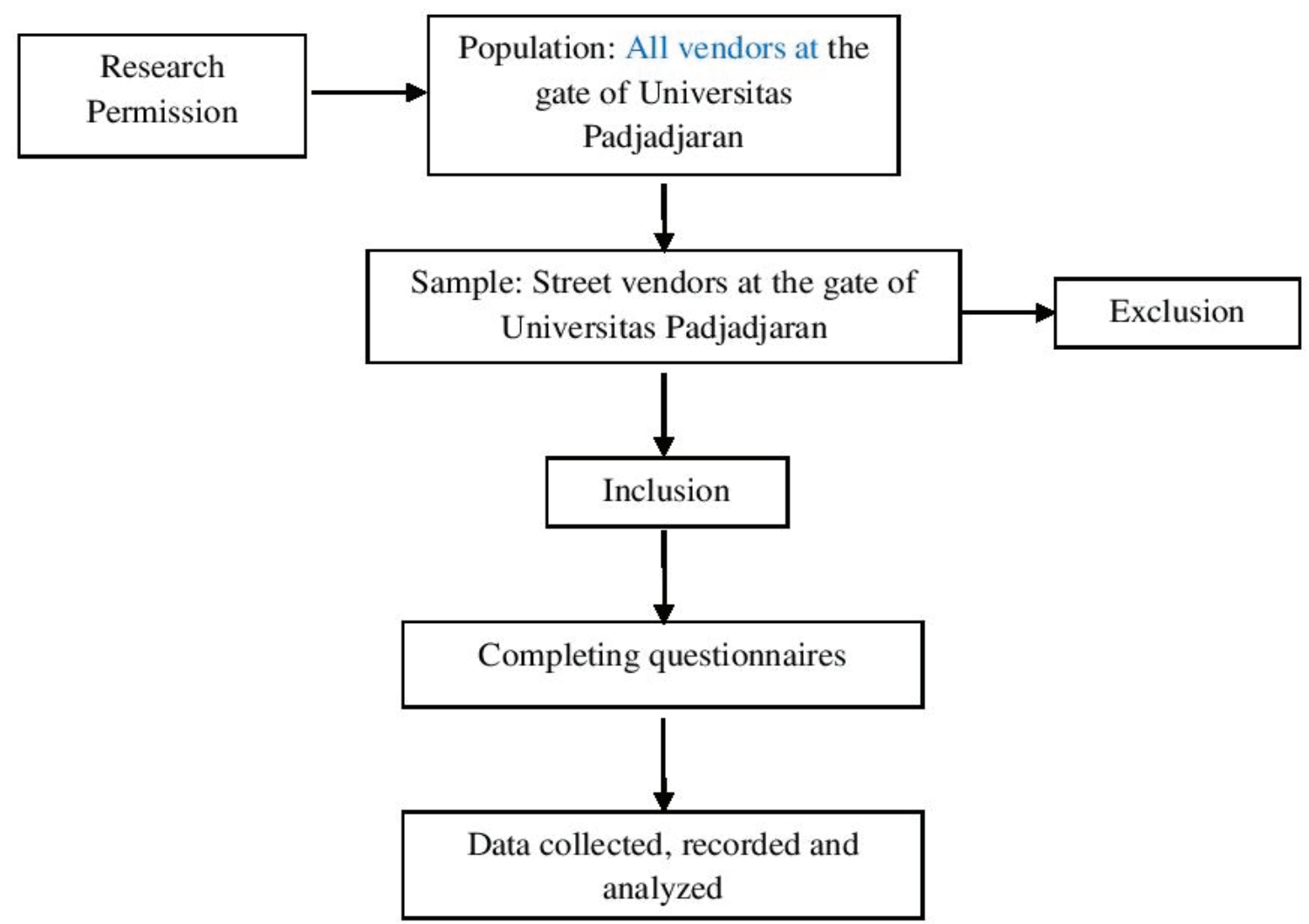

Figure 1 Flow of Study

with fixed stalls, or semi-fixed stalls that sell various kinds of items. The items sold by the vendors include food, drinks, merchandise and cloths. ${ }^{9}$ As street vendors sell food, they have the possibilities of becoming agent for food borne disease. In order to reduce the incidence of food borne disease, assessment of hand washing among street vendors needs to be conducted.

In this study, the levels of knowledge, attitude and practice of hand washing among street vendors at the gate of Universitas Padjadjaran Campus were evaluated. By knowing the information regarding hand washing among street vendors, a preventive measure can be taken to reduce incidence of diarrhea.

\section{Methods}

A cross-sectional descriptive study was conducted at a single point of time. The respondents were street vendors at the gate Universitas Padjadjaran Campus as most of the street vendors were located at this place. There were 33 workers eligible to participate in this study with inclusion criteria involved in food preparation, cooking and mixing. Many street vendors who refused to participate were excluded. The study was performed from June to November 2012.

Knowledge of hand washing was defined as how much information the respondents have regarding hand washing such as the procedure, the objective and the timing of hand washing. The knowledge was later classified as good if the score ranged from 12-18, moderate if the score ranged from 6-11 and poor if the score ranged from 0-5. Attitude of hand washing was defined as how they reflected towards the hand washing such as when they should perform hand washing. The level of attitude was classified as good if the score ranged from $40-55$, moderate if the score ranged from $30-$ 49 and poor if the score ranged from 11-25. Practice of hand washing was defined as how well the respondents washed their hands such as whether they performed all of the hand washing procedure. Same with knowledge and attitude, the practice was also classified as good if the score ranged from 50-70, moderate if the score ranged from 30-49 and poor if the 
Table1 Score of Knowledge Question according to Sex

\begin{tabular}{lcccc}
\hline & & \multicolumn{2}{c}{ Sex } & \\
\cline { 2 - 3 } & & $\begin{array}{c}\text { Female } \\
\text { (n) }\end{array}$ & $\begin{array}{c}\text { Male } \\
\text { (n) }\end{array}$ & Total \\
\hline Objective of hand washing & 0 & 3 & 23 & 26 \\
Characteristics of clean water & 1 & 2 & 2 & 4 \\
Basic material for hand washing & 0 & 4 & 23 & 27 \\
Example of diseases can be prevented by hand & 1 & 1 & 2 & 3 \\
washing & 1 & 1 & 16 & 17 \\
Basic steps of hand washing & 2 & 4 & 9 & 13 \\
& 1 & 0 & 4 & 4 \\
& 2 & 5 & 15 & 20 \\
Timing of hand washing & 0 & 0 & 6 & 6 \\
(before or after certain events & 1 & 2 & 9 & 11 \\
& 2 & 0 & 3 & 3 \\
& 3 & 2 & 4 & 6 \\
& 5 & 0 & 1 & 1 \\
& 6 & 0 & 1 & 1 \\
& 7 & 1 & 1 & 1 \\
& 1 & 0 & 6 & 7 \\
& 2 & 3 & 4 & 4 \\
& 3 & 0 & 8 & 8 \\
& 4 & 2 & 8 & 8 \\
& & & & 10 \\
\hline
\end{tabular}

score ranged from 14-29.

A questionnaire has been used in conducting this study. The questionnaire was validated and undergoing a reliability test prior to the study. The questionnaire consisted of three sections which were 6 questions about knowledge, 11 statements about attitude and 14 statements about practice. The respondents were given informed consent before the interview session. The data collected were recorded and analyzed by using computer. The flow of the study can be seen in Figure 1.

\section{Results}

There were 30 people who participated in the study and 3 people refused. Knowledge of hand washing was assessed by measuring how much the respondents knew about hand washing. The knowledge being assessed were the purpose of hand washing, preparation, material needed, the steps of hand washing and the timing of hand washing. In this section, there were 6 questions given, and the score can be seen in Table 1 . As the result, there were 9 respondents classified as good, 12 respondents classified as moderate and 9 respondents classified as poor.

In the attitude section, the respondent's reactions towards hand washing were evaluated. There were 11 statements used to assess the attitude of the respondents, divided into 2 parts, before and after certain events. By using their opinion, the respondents answered the question by choosing strongly agree, agree, neutral, disagree and strongly disagree. The results of the respondents' attitude can be seen in Table 2.

In the last section, how well the respondents performed hand washing was assessed. There were 14 statements asked in this section, divided into 3 parts to evaluate the practice of the respondents regarding hand washing. The respondents answered this section by the 
Table 2 Score for Hand washing before certain events according to Sex

\begin{tabular}{llccc}
\hline & & \multicolumn{2}{c}{ Sex } & \\
\cline { 2 - 3 } & & $\begin{array}{c}\text { Female } \\
\text { (n) }\end{array}$ & $\begin{array}{c}\text { Male } \\
\text { (n) }\end{array}$ & Total \\
\hline Preparing food & Disagree & 0 & 2 & 2 \\
& Neutral & 0 & 1 & 1 \\
& Agree & 3 & 13 & 16 \\
& Strongly Agree & 2 & 9 & 11 \\
Processing food & Strongly Disagree & 0 & 1 & 1 \\
& Agree & 2 & 12 & 14 \\
Handling cooking utensils & Strongly Agree & 3 & 12 & 15 \\
& Strongly Disagree & 0 & 1 & 1 \\
& Disagree & 0 & 4 & 4 \\
& Neutral & 0 & 5 & 5 \\
Agree & 4 & 11 & 15 \\
& Strongly Agree & 1 & 4 & 5 \\
& Strongly Disagree & 0 & 1 & 1 \\
& Neutral & 0 & 1 & 1 \\
& Agree & 2 & 15 & 17 \\
& Strongly Agree & 3 & 8 & 11 \\
& Disagree & 1 & 3 & 4 \\
& Neutral & 0 & 2 & 2 \\
& Agree & 3 & 11 & 14 \\
& Strongly Agree & 1 & 9 & 10 \\
\hline \multirow{5}{*}{ Processing raw food } & & & &
\end{tabular}

same manner in attitude section according to their practice. The result of the practice can be seen in Table 4.

\section{Discussions}

There are possibilities that the respondents still did not understand the reason of hand washing as seen from the questions regarding objective of hand washing in Table 1 . There were only 4 people who gave the correct answers while the others gave incorrect answers. Basically hand washing is done to avoid someone from spreading disease to other person. ${ }^{10}$ Running water is a one of the characteristics of clean water. However, due to lack of facilities, most of them ignored about this and only used water from a bucket. This can be seen in the questions regarding characteristics of clean water, which 27 of them answered incorrectly and only 13 respondents attained full score for questions regarding basic material for hand washing. Fortunately, they still understood the

Table 3 Level of Attitude and Practice of Hand washing

\begin{tabular}{lcc}
\hline & Attitude & Practice \\
\cline { 2 - 4 } & $\mathrm{N}$ & $\mathrm{N}$ \\
\hline Moderate & 5 & 5 \\
Good & 25 & 25 \\
Total & 30 & 30 \\
\hline
\end{tabular}


importance of using soap in hand washing. ${ }^{10,11}$ According to Aseptic Processing Workbook, there are seven steps of hand washing. Start with rubbing both palms together, then back of hands with interlacing fingers, and front of hands also with interlacing fingers. Continue with clasping fingers and rub the back of finger, rub around thumbs and fingertips to palm in rotating manner. Last but not least, rub around the wrists. ${ }^{12}$ Only 7 respondents got full score in questions regarding the basic steps of hand washing, showing that they were still confused about the basic steps of hand washing. More than half of them achieved good score in the questions regarding timing of hand washing. It showed that they were aware when they should wash their hands. As food handlers, the respondents should wash their hands after using the toilet, after sneezing or coughing, after handling garbage and after doing activities that make their hands dirty such as handling money. ${ }^{10,11}$

From the results, it can be seen that most of the respondents had a good understanding about the indication of hand washing before certain events. Referring to question regarding whether the respondents should wash their hand before handling the utensils for cooking, it has the lowest number of respondents who agreed with the statements. However, still more than half of the respondents agreed with the statements of this question. The indications for hand washing are washing hand before, during, and after preparing food, handling ready-to-eat or raw foods, touching serving utensils, before handling different foods, serving foods and eating food. ${ }^{10,11}$

Furthermore in the question regarding whether they should wash their hand after handling garbage, all of the respondents agreed with the statements proving that they had a good attitude toward hand washing. In addition, the respondents also need to wash their hand after using the toilet, after touching bare human body parts, after handling cleaning chemicals and after doing other activities that make their hands dirty. ${ }^{10,11}$

In the practice section, not only the basic steps of hand washing were assessed, but the preparation and extra step of hand washing for food handlers were also asked. The respondents needed to remove their jewelry before performing hand washing. ${ }^{11}$ Only 13 respondents agreed with this statement, showing that they did not fully understand how to practice hand washing as a food handler. There were several questions regarding basic steps of hand washing, more than half of the respondents agreed with the statements of those questions. This shows that the respondents had a good practice of basic hand washing. The basic steps of hand washing start with rubbing the palm together. Then, rub back of hands with interlacing fingers and front of hands also with interlacing fingers. After that, continue with clasping fingers and rub the back of finger, rub around thumbs and fingertips to palm in rotating manner. Lastly, rub around the wrists. ${ }^{12}$

In conclusion, $12 / 30$ respondents had a moderate level of knowledge of hand washing, while the other 18 respondents were distributed evenly to good and poor level of knowledge. For attitude and practice, 25/30 respondents were categorized as having good level of hand washing. Only 5 respondents had a moderate level of hand washing for both attitude and practice.

Compared to a previous study on hand washing by housewives, both housewives and street vendors had moderate level of knowledge and good level of attitude of hand washing. However, the housewives had poor level of practice while the street vendors had good level of practice of hand washing. ${ }^{3}$

In order to improve the street vendors' condition, a campaign regarding hand washing for food handlers should be conducted. Education regarding the importance and the right way of performing hand washing can be also included in the campaign. Providing better facilities also can promote hand washing among the respondents. Other than improving the respondents condition, this study can be continued by assessing the source and the cleanliness of the water used by the respondents. Furthermore, the healthy behavior of the respondents other than hand washing can be also assessed for a future study.

\section{References}

1. Lopez AD, Mathers CD, Ezzati M, Jamison DT, Murray CJL, editors. Global burden of disease and risk factor. Washington (DC): a copublication of The World Bank and Oxford University Press; 2006.

2. WHO. Global burden of disease (GBD). World Health Organization (WHO); 2011. [cited 2012 January 5]. Available from: http://www.who.int/healthinfo/global_ burden_disease/.

3. Webber R. Communicable disease epidemiology and control: a global perspective. Oxfordshire: Cabi; 2009.

4. CDC. CDC 2011 estimates fooborne illness. 
Centers for Disease Control and Prevention (CDC); 2010 [cited 2012 September 12]. Available from: http://www.cdc.gov/ foodborneburden /2011-foodborneestimates.html.

5. Bjorklund R. Food borne illnesses. New York: Marshall Cavendish Benchmark; 2006.

6. WHO. The global burden of disease 2004 update; 2008 [cited 2012 September 12]. Available from: http://www.who.int/ healthinfo/global_burden_disease/GBD report_2004update.

7. Water Sanitation Health (WSH). Waterrelated disease. WHO; 2012 [cited 2012 January 5] Available from: http://www. who.int/water_sanitation_health/ diseases/diarrhoea/.

8. Luby SP, Agboatwalla M, Painter J, Altaf A, Billhimer WL, Hoekstra RM. Effect of intensive handwashing promotion on childhood diarrhea in high-risk communities in Pakistan: a randomized controlled trial. JAMA. 2004;
291(21):2547-54.

9. Women in informal employment: globalizing and organizing (WIEGO). Street vendors; 2012 [cited 2012 May 9]. Available from: http://wiego.org/ informal-economy/occupational-groups/ street-vendors.

10. CDC. Handwashing: clean hands save lifes. [cited 2012 April 30] Available from: http://www.cdc.gov/handwashing/.

11. Simonne A. Proper hand washing for food handlers. Institute of Food and Agricultural Sciences, University of Florida; 2005 [updated October 2011]; [Cited 2012 May 12] Available from: http://edis.ifas.ufl. edu/.

12. Alison B, Tim S, editors. Aseptic processing workbook. Leeds: University of Leeds; 2010.

13. Pratama IK. Gambaran pengetahuan, praktik dan sikap terhadap cuci tangan dikalangan ibu rumah tangga di Desa Hegarmanah dan Sayang [Minor Thesis]. Bandung: Universitas Padjadjaran; 2012. 